\title{
Complex Dynamics of Jungck Ishikawa Iterates for Hyperbolic Cosine Function
}

\author{
Suman Pant \\ Research Scholar \\ G. B. Pant Eng. College, \\ Pauri Garhwal
}

\author{
Yashwant S. Chauhan, \\ Ph.D \\ Assistant Professor \\ G. B. Pant Eng. College, \\ Pauri Garhwal
}

\author{
Priti Dimri, Ph.D \\ Asso. Professor and Head \\ G. B. Pant Eng. College, \\ Pauri Garhwal
}

\begin{abstract}
The dynamics of transcendental function is one of emerging and interesting field of research nowadays. We introduce in this paper the complex dynamics of hyperbolic cosine function of the type $\left\{\cosh \left(\mathrm{z}^{\mathrm{n}}\right)+\mathrm{z}+\mathrm{c}=0\right\}$ and applied Jungck Ishikawa iteration to generate new Relative Superior Mandelbrot set and Relative Superior Julia set. In order to solve this function by Jungck -type iterative schemes, we write it in the form of $\mathrm{Sz}=\mathrm{Tz}$, where the function $\mathrm{T}, \mathrm{S}$ are defined as $\mathrm{Tz}=\cosh \left(\mathrm{z}^{\mathrm{n}}\right)+\mathrm{c}$ and $\mathrm{Sz}=-\mathrm{z}$. Only mathematical explanations are derived by applying Jungck Ishikawa Iteration for transcendental function in the literature but in this paper we have generated relative Mandelbrot sets and Relative Julia sets.
\end{abstract}

\section{Keywords}

Complex dynamics, Relative Superior Mandelbrot set, Relative Julia set, Jungck Ishikawa Iteration

\section{INTRODUCTION}

The study of dynamical behavior of the transcendental functions was initiated by Fatou [12]. For transcendental function, points with unbounded orbits are not in Fatou sets but they must lie in Julia sets.

In complex analysis, the hyperbolic functions arise as the imaginary parts of sine and cosine. When considered defined by a complex variable, the hyperbolic functions are rational functions of exponentials, and are hence meromorphic.

In this past literature the cosine function was considered of the following forms:
(i) $\cos \left(\mathrm{z}^{\mathrm{n}}\right)+\mathrm{c}=0$
(ii) $(\cos \mathrm{z}+\mathrm{c})^{\mathrm{n}}=0$
(iii) $\operatorname{acos}\left(\mathrm{z}^{\mathrm{n}}\right)+\mathrm{c}=0$
(iv) $(\operatorname{acos}(\mathrm{z})+\mathrm{c})^{\mathrm{n}}=0$

But now we have used hyperbolic cosine function of the type $\cosh \left(\mathrm{z}^{\mathrm{n}}\right)+\mathrm{z}+\mathrm{c}=0$ where $\mathrm{n} \geq 2$ and applied Jungck Ishikawa iterates to develop fractal images of this transcendental function. Escape criteria of polynomials are used to generate Relative Superior Mandelbrot Sets and Relative Superior Julia Sets. Our results are different from existing results in literature.

\section{PRELIMINARIES}

The process of generating fractal images from $\mathrm{z} \rightarrow \cosh \left(\mathrm{z}^{\mathrm{n}}\right)+\mathrm{z}+\mathrm{c}$ is similar to the one employed for the self-squared function [17]. Briefly, this process consists of iterating this function up to $\mathrm{N}$ times.

Starting from a value $\mathrm{z}_{0}$ we obtain $\mathrm{z} 1, \mathrm{z}_{2}, \mathrm{z}_{3}, \mathrm{z}_{4} \ldots$ by applying the transformation $\mathrm{z} \rightarrow \cosh \left(\mathrm{z}^{\mathrm{n}}\right)+\mathrm{z}+\mathrm{c}$

\subsection{Ishikawa Iteration [8]}

Let $X$ is a subset of real or complex numbers and $T: X \rightarrow$ $X$ for $x_{0} \in X$, we have the sequences $\left\{x_{n}\right\}$ and $\left\{y_{n}\right\}$ in $X$ in the following manner:

$\mathrm{x}_{\mathrm{n}+1}=\alpha_{\mathrm{n}} \mathrm{T} \mathrm{y}_{\mathrm{n}}+\left(1-\alpha_{\mathrm{n}}\right) \mathrm{x}_{\mathrm{n}}$

$\mathrm{y}_{\mathrm{n}}=\beta_{\mathrm{n}} \mathrm{T} \mathrm{x}_{\mathrm{n}}+\left(1-\beta_{\mathrm{n}}\right) \mathrm{x}_{\mathrm{n}}$

where $0 \leq \beta_{\mathrm{n}} \geq 1$ and $0 \leq \alpha_{\mathrm{n}} \geq 1$ and $\alpha_{\mathrm{n}} \& \beta_{\mathrm{n}}$ both convergent to non zero number.

\subsection{Definition [14]}

The sequences $\left\{x_{n}\right\}$ and $\left\{y_{n}\right\}$ constructed above is called Ishikawa sequences of iteration or relative superior sequences of iterates. We denote it by $\left(x_{0}, \alpha_{n}, \beta_{n}, t\right)$. Notice that RSO $\left(\mathrm{x}_{0}, \alpha_{\mathrm{n}}, \beta_{\mathrm{n}}, \mathrm{t}\right)$ with $\beta_{\mathrm{n}}=1$ is $\operatorname{RSO}\left(\mathrm{x}_{0}, \alpha_{\mathrm{n}}, \mathrm{t}\right)$ i.e. Mann's orbit and if we place $\alpha_{n}=\beta_{n}=1$ then RSO $\left(x_{0}, \alpha_{n}, \beta_{n}, t\right)$ reduces to $\mathrm{O}\left(\mathrm{x}_{0}, \mathrm{t}\right)$.We remark that Ishikawa orbit $\operatorname{RSO}\left(\mathrm{x}_{0}, \alpha_{\mathrm{n}}, \beta_{\mathrm{n}}, \mathrm{t}\right)$ with $\beta_{n}=1 / 2 \quad$ is Relative superior orbit. Now we define Julia set for function with respect to Ishikawa iterates. We call them as Relative Superior Julia sets.

\subsection{Definition [14]}

The set of points SK whose orbits are bounded under Relative superior iteration of function Q (z) is called Relative Superior Julia sets. Relative Superior Julia set of Q is a boundary of Julia set RSK.

\subsection{Jungck Ishikawa Iteration [16]}

Let $(X,\|\|$.$) be a Banach space and Y$ an arbitrary set. Let $S$, $\mathrm{T}: \mathrm{Y} \rightarrow \mathrm{X}$ be two non self-mappings such that $\mathrm{T}(\mathrm{Y}) \subseteq \mathrm{S}(\mathrm{Y})$, $\mathrm{S}(\mathrm{Y})$ is a complete subspace of $\mathrm{X}$ and $\mathrm{S}$ is injective. Then for $\mathrm{x}_{\mathrm{o}} \in \mathrm{Y}$, define the sequence $\left\{\mathrm{S}_{\mathrm{n}}\right\}$ iteratively by

$$
\begin{aligned}
& S x_{n+1}=\alpha_{n} T y_{n}+\left(1-\alpha_{n}\right) S x_{n} \\
& S y_{n}=\beta_{n} T x_{n}+\left(1-\beta_{n}\right) S x_{n}
\end{aligned}
$$

where $0 \leq \beta_{\mathrm{n}} \geq 1$ and $0 \leq \alpha_{\mathrm{n}} \geq 1$ and $\alpha_{\mathrm{n}} \& \beta_{\mathrm{n}}$ both convergent to non zero number.

\section{GENERATING THE FRACTALS}

Fractals have been generated from, using escape-time techniques-

\subsection{Escape Criterion for Quadratics [14]}


Suppose that $|\mathrm{z}|>\max \left\{|\mathrm{c}|, 2 / \mathrm{s}, 2 / \mathrm{s}{ }^{\prime}\right\}$, then $\left|\mathrm{z}_{\mathrm{n}}\right|>(1+\lambda)^{\mathrm{n}}|\mathrm{z}|$ and $\left|\mathrm{z}_{\mathrm{n}}\right| \rightarrow \infty$ as $\mathrm{n} \rightarrow \infty$. So, $|\mathrm{z}| \geq \mathrm{c} \mid$, and $|\mathrm{z}|>2 / \mathrm{s}$ as well as $|\mathrm{z}|>2 / \mathrm{s}$ ' shows the escape criteria for quadratics.

\subsection{Escape Criterion for Cubics[14]}

Suppose that $|z|>\max \left\{|b|,(a+2 / s)^{1 / 2},\left(a+2 / s^{\prime}\right) 1 / 2\right\}$, then $\left|z_{n}\right| \rightarrow \infty$ as $n \rightarrow \infty$.This gives the escape criteria for cubic polynomials.

\subsection{General Escape Criterion [14]}

Suppose that $|z|>\max \left\{|b|,(a+2 / s)^{1 / 2},\left(a+2 / s^{\prime}\right)^{1 / 2}\right\}$, then $\left|\mathrm{z}_{\mathrm{n}}\right| \rightarrow \infty$ as $\mathrm{n} \rightarrow \infty$ is the general escape criteria.

\section{FIXED POINTS}

\subsection{Fixed points of quadratic function}

Table 1: Orbit of $\mathbf{F}(\mathrm{z})$ for $\left(\mathrm{z}_{\mathbf{0}}=\mathbf{- 0 . 8 1 2 5 - 0 . 1 1 2 5 i )}\right.$ at $\alpha=0.5$,

$$
\beta=0.5, \mathbf{c}=0.1
$$

\begin{tabular}{|c|c|c|c|}
\hline $\begin{array}{c}\text { No. of } \\
\text { iterations }\end{array}$ & $|\mathrm{Tz}|$ & $\begin{array}{c}\text { No. of } \\
\text { iterations }\end{array}$ & $|\mathrm{Tz}|$ \\
\hline 1 & 1.30289 & 11 & 1.32199 \\
\hline 2 & 1.31711 & 12 & 1.32223 \\
\hline 3 & 1.32285 & 13 & 1.32217 \\
\hline 4 & 1.32199 & 14 & 1.32219 \\
\hline 5 & 1.32223 & 15 & 1.32219 \\
\hline 6 & 1.32217 & 16 & 1.32219 \\
\hline 7 & 1.32199 & 17 & 1.32219 \\
\hline 8 & 1.32223 & 18 & 1.32199 \\
\hline 9 & 1.32217 & 19 & 1.32223 \\
\hline 10 & 1.32219 & 20 & 1.32217 \\
\hline
\end{tabular}

Here we observe that the value converges to a fixed point 1.32219 after 6 iterations.

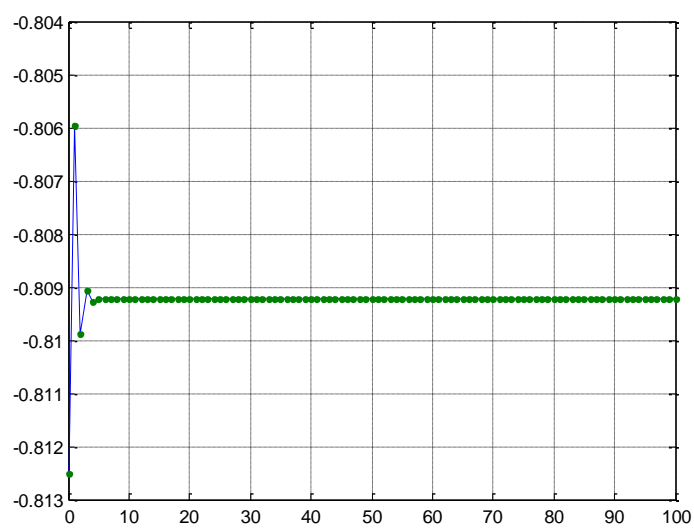

Figure 1: Orbit of $\mathbf{F}(\mathrm{z})$ for $\left(\mathrm{z}_{\mathbf{0}}=\mathbf{- \mathbf { 0 . 8 1 2 5 } - 0 . 1 1 2 5 i )}\right.$ at $\alpha=\mathbf{0 . 5}$,

$$
\beta=0.5, \mathbf{c}=0.1
$$

Table 2: Orbit of $\mathrm{F}(\mathrm{z})$ for $\left(\mathrm{z}_{\mathbf{0}}=\mathbf{- 2 . 6 8 7 5 - 0 . 0 6 2 5 i}\right)$ at $\alpha=0.8$, $\beta=0.1, \mathbf{c}=0.1$

\begin{tabular}{|c|c|c|c|}
\hline $\begin{array}{c}\text { No of } \\
\text { Iterations }\end{array}$ & $|\mathrm{Tx}|$ & $\begin{array}{c}\text { No of } \\
\text { Iterations }\end{array}$ & $|\mathrm{Tx}|$ \\
\hline 71 & 74.025 & 86 & 1.1217 \\
\hline 72 & 1.1217 & 87 & 74.0253 \\
\hline 73 & 74.0256 & 88 & 1.1217 \\
\hline 74 & 1.1217 & 89 & 74.0253 \\
\hline 75 & 74.0251 & 90 & 1.1217 \\
\hline 76 & 1.1217 & 91 & 74.0253 \\
\hline
\end{tabular}

\begin{tabular}{|c|c|c|c|}
\hline 77 & 74.0255 & 92 & 1.1217 \\
\hline 78 & 1.1217 & 93 & 74.0253 \\
\hline 79 & 74.0252 & 94 & 1.1217 \\
\hline 80 & 1.1217 & 95 & 74.0253 \\
\hline 81 & 74.0254 & 96 & 1.1217 \\
\hline 82 & 1.1217 & 97 & 74.0253 \\
\hline 83 & 74.0253 & 98 & 1.1217 \\
\hline 84 & 1.1217 & 99 & 74.0253 \\
\hline 85 & 74.0254 & 100 & 1.1217 \\
\hline
\end{tabular}

Here we 70 iterations and observed that the value converges to two fixed points $\mathbf{7 4 . 0 2 5 3}$ and $\mathbf{1 . 1 2 1 7}$ after 87 iterations.

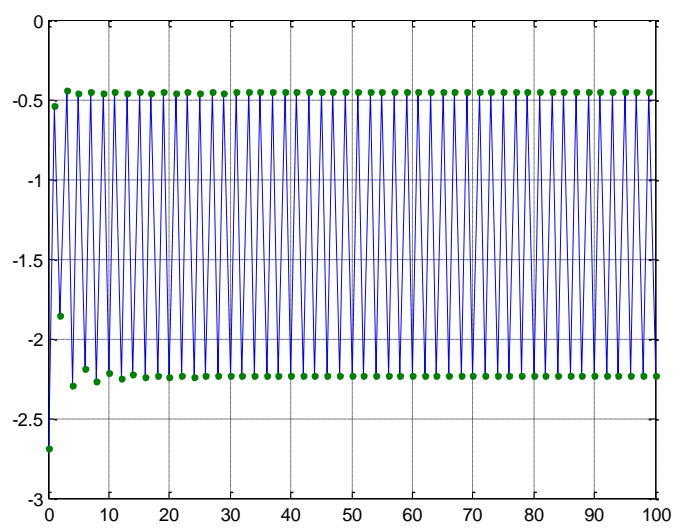

Figure 2. Orbit of $F(z)$ for $\left(z_{0}=\mathbf{- 2 . 6 8 7 5 - 0 . 0 6 2 5 i )}\right.$ at $\alpha=0.8, \beta=0.1, \mathrm{c}=0.1$

Table 3: Orbit of $\mathrm{F}(\mathrm{z})$ for $\left(\mathrm{z}_{\mathbf{0}}=-\mathbf{0 . 3 5 6 2 5 - 1 . 6 5 i}\right)$ at $\alpha=0.3$,

$$
\beta=0.7, \mathbf{c}=0.1
$$

\begin{tabular}{|c|c|c|c|}
\hline $\begin{array}{c}\text { No. of } \\
\text { iterations }\end{array}$ & $|\mathrm{Tz}|$ & $\begin{array}{c}\text { No. of } \\
\text { iterations }\end{array}$ & $|\mathrm{Tz}|$ \\
\hline 1 & 6.71552 & 11 & 1.26349 \\
\hline 2 & 1.99943 & 12 & 1.26342 \\
\hline 3 & 1.21717 & 13 & 1.26339 \\
\hline 4 & 0.88466 & 14 & 1.26338 \\
\hline 5 & 1.13628 & 15 & 1.26338 \\
\hline 6 & 1.26549 & 16 & 1.26338 \\
\hline 7 & 1.26856 & 17 & 1.26338 \\
\hline 8 & 1.26571 & 18 & 1.26338 \\
\hline 9 & 1.26426 & 19 & 1.26338 \\
\hline 10 & 1.26370 & 20 & 1.26338 \\
\hline
\end{tabular}

Here we observed that the value converges to a fixed point $\mathbf{1 . 2 6 3 3 8}$ after 13 iterations. 


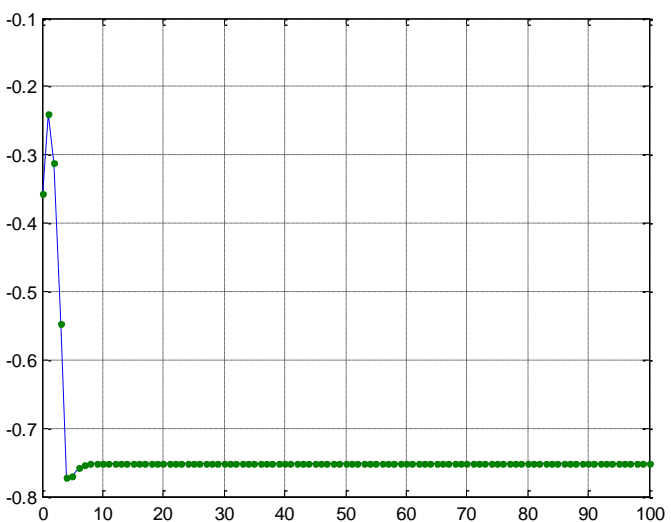

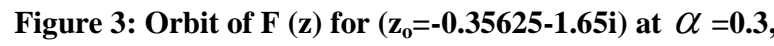
$\beta=0.7, \mathbf{c}=0.1$

\subsection{Fixed points of cubic function}

Table 1: Orbit of $F(z)$ for $\left(z_{0}=-0.9+1.04375\right)$ at $\alpha=0.5, \beta$ $=0.7, \mathrm{c}=0.1$

\begin{tabular}{|c|c|c|c|}
\hline $\begin{array}{c}\text { No. of } \\
\text { iterations }\end{array}$ & $|\mathrm{Tz}|$ & $\begin{array}{c}\text { No. of } \\
\text { iterations }\end{array}$ & $|\mathrm{Tz}|$ \\
\hline 51 & 2.889998 & 66 & 1.327397 \\
\hline 52 & 1.327397 & 67 & 2.890001 \\
\hline 53 & 2.890004 & 68 & 1.327397 \\
\hline 54 & 1.327397 & 69 & 2.890001 \\
\hline 55 & 2.89000 & 70 & 1.327397 \\
\hline 56 & 1.327397 & 71 & 2.890001 \\
\hline 57 & 2.89000 & 72 & 1.327397 \\
\hline 58 & 1.327397 & 73 & 2.890001 \\
\hline 59 & 2.890001 & 74 & 1.327397 \\
\hline 60 & 1.327397 & 75 & 2.890001 \\
\hline 61 & 2.890001 & 76 & 1.327397 \\
\hline 62 & 1.327397 & 77 & 2.890001 \\
\hline 63 & 2.890001 & 78 & 1.327397 \\
\hline 64 & 1.327397 & 79 & 2.890001 \\
\hline 65 & 2.890001 & 80 & 1.327397 \\
\hline
\end{tabular}

Here we skipped 50 iterations and observed that the value converges to two fixed points $\mathbf{2 . 8 9 0 0 0 1}$ and $\mathbf{1 . 3 2 7 3 9 7}$ after 58 iterations.

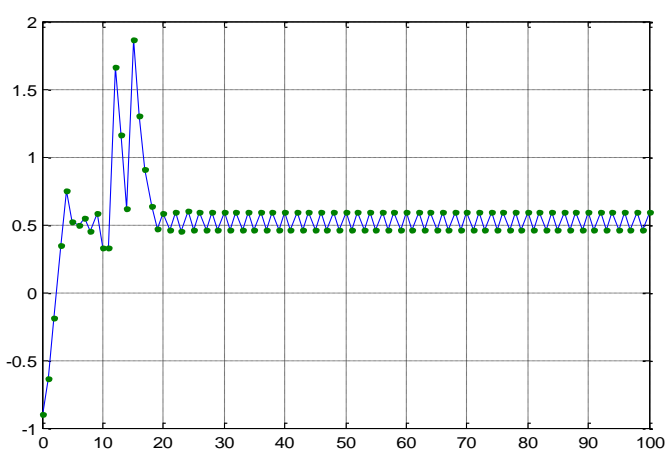

Figure 1: Orbit of $F(z)$ for $\left(z_{0}=-0.9+1.04375\right)$ at $\alpha=0.5$, $\beta=0.7, \mathbf{c}=0.1$
Table 2: Orbit of $\mathbf{F}(\mathrm{z})$ for $\left(\mathrm{z}_{0}=-1.31875+1.1225 i\right)$ at $\alpha$ $=0.3, \beta=0.5, \mathbf{c}=0.1$

\begin{tabular}{|c|c|c|c|}
\hline $\begin{array}{c}\text { No. of } \\
\text { iterations }\end{array}$ & $|\mathrm{Tz}|$ & $\begin{array}{c}\text { No. of } \\
\text { iterations }\end{array}$ & $|\mathrm{Tz}|$ \\
\hline 11 & 1.3534 & 26 & 1.3392 \\
\hline 12 & 1.3127 & 27 & 1.3384 \\
\hline 13 & 1.3605 & 28 & 1.3388 \\
\hline 14 & 1.3293 & 29 & 1.3387 \\
\hline 15 & 1.3381 & 30 & 1.3386 \\
\hline 16 & 1.3445 & 31 & 1.3388 \\
\hline 17 & 1.3322 & 32 & 1.3386 \\
\hline 18 & 1.3431 & 33 & 1.3387 \\
\hline 19 & 1.3373 & 34 & 1.3387 \\
\hline 20 & 1.3379 & 35 & 1.3387 \\
\hline 21 & 1.3404 & 36 & 1.3387 \\
\hline 22 & 1.3372 & 37 & 1.3387 \\
\hline 23 & 1.3395 & 38 & 1.3387 \\
\hline 24 & 1.3386 & 39 & 1.3387 \\
\hline 25 & 1.3384 & 40 & 1.3387 \\
\hline
\end{tabular}

Here we skipped 10 iterations and observed that the value converges to a fixed point $\mathbf{1 . 3 3 8 7}$ after 32 iterations.

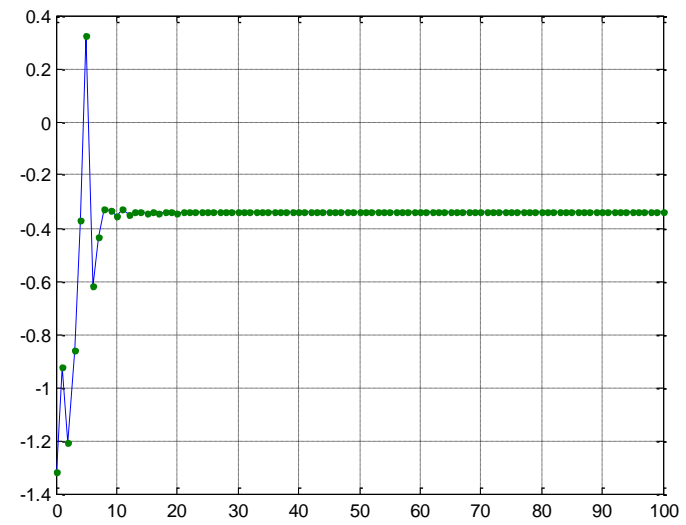

Figure 2: Orbit of $\mathrm{F}(\mathrm{z})$ for $\left(\mathrm{z}_{\mathbf{0}}=-\mathbf{1 . 3 1 8 7 5}+1.1225 \mathrm{i}\right)$ at $\alpha$ $=0.3, \beta=0.5, \mathbf{c}=0.1$

Table 3: Orbit of $\mathrm{F}(\mathrm{z})$ for $\left(\mathrm{z}_{0}=\mathbf{- 1 . 9 2 5 - 1 . 7 3 7 5 i}\right)$ at $\alpha=\mathbf{0 . 3}$, $\beta=0.2, \mathbf{c}=0.1$

\begin{tabular}{|c|c|c|c|}
\hline $\begin{array}{c}\text { No of } \\
\text { Iterations }\end{array}$ & $|\mathrm{Tx}|$ & $\begin{array}{c}\text { No of } \\
\text { Iterations }\end{array}$ & $|\mathrm{Tx}|$ \\
\hline 1 & 14879.0392 & 16 & 1.60569 \\
\hline 2 & 17.11398 & 17 & 1.60569 \\
\hline 3 & 1.50879 & 18 & 1.60566 \\
\hline 4 & 4.78429 & 19 & 1.60567 \\
\hline 5 & 1.53148 & 20 & 1.60567 \\
\hline 6 & 1.47782 & 21 & 1.60567 \\
\hline 7 & 1.66984 & 22 & 1.60567 \\
\hline 8 & 1.60781 & 23 & 1.60567 \\
\hline 9 & 1.59224 & 24 & 1.60567 \\
\hline 10 & 1.61045 & 25 & 1.60567 \\
\hline 11 & 1.60660 & 26 & 1.60567 \\
\hline 12 & 1.60431 & 27 & 1.60567 \\
\hline 13 & 1.60601 & 28 & 1.60567 \\
\hline
\end{tabular}




\begin{tabular}{|l|l|l|l|}
\hline 14 & 1.60582 & 29 & 1.60567 \\
\hline 15 & 1.60554 & 30 & 1.60567 \\
\hline
\end{tabular}

Here we observe that the value converges to a fixed point $\mathbf{1 . 6 0 5 6 7}$ after 18 iterations.

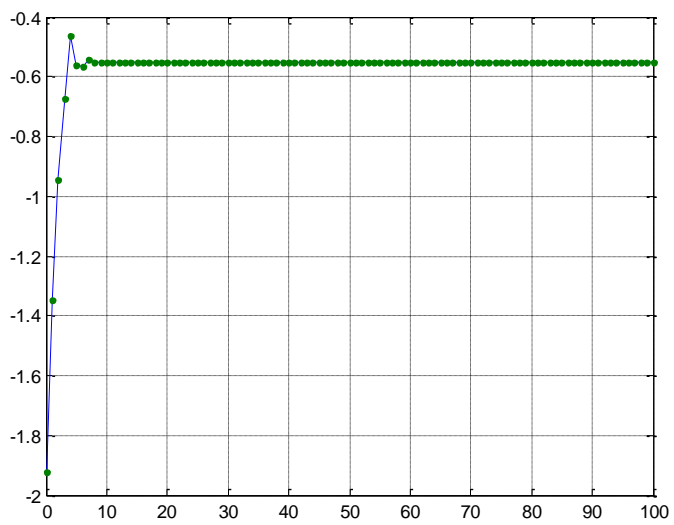

Figure 3: Orbit of $\mathrm{F}(\mathrm{z})$ for $\left(\mathrm{z}_{\mathbf{0}}=\mathbf{- 1 . 9 2 5 - 1 . 7 3 7 5 i )}\right.$ at $\alpha=\mathbf{0 . 3}$, $\beta=0.2, \mathbf{c}=0.1$

\subsection{Fixed points of biquadratic function}

Table 1: Orbit of $\mathbf{F}(\mathrm{z})$ for $\left(\mathrm{z}_{0}=\mathbf{- 2 . 6 6 8 7 5 + 0 . 0 0 6 2 5 i}\right)$ at $\alpha$ $=0.5, \beta=0.5, c=0.1$

\begin{tabular}{|c|c|c|c|}
\hline $\begin{array}{c}\text { No. of } \\
\text { iterations }\end{array}$ & $|\mathrm{Tz}|$ & $\begin{array}{c}\text { No. of } \\
\text { iterations }\end{array}$ & $|\mathrm{Tz}|$ \\
\hline 21 & 1.1097 & 36 & 2.1494 \\
\hline 22 & 2.1476 & 37 & 1.1097 \\
\hline 23 & 1.1097 & 38 & 2.1494 \\
\hline 24 & 2.1485 & 39 & 1.1097 \\
\hline 25 & 1.1097 & 40 & 2.1494 \\
\hline 26 & 2.1490 & 41 & 1.1097 \\
\hline 27 & 1.1097 & 42 & 2.1494 \\
\hline 28 & 2.1492 & 43 & 1.1097 \\
\hline 29 & 1.1097 & 44 & 2.1494 \\
\hline 30 & 2.1493 & 45 & 1.1097 \\
\hline 31 & 1.1097 & 46 & 2.1494 \\
\hline 32 & 2.1493 & 47 & 1.1097 \\
\hline 33 & 1.1097 & 48 & 2.1494 \\
\hline 34 & 2.1494 & 49 & 1.1097 \\
\hline 35 & 1.1097 & 50 & 2.1494 \\
\hline
\end{tabular}

Here we skipped 20 iterations and observed that the value converges to two fixed points $\mathbf{1 . 1 0 9 7}$ and $\mathbf{2 . 1 4 9 4}$ after 32 iterations.

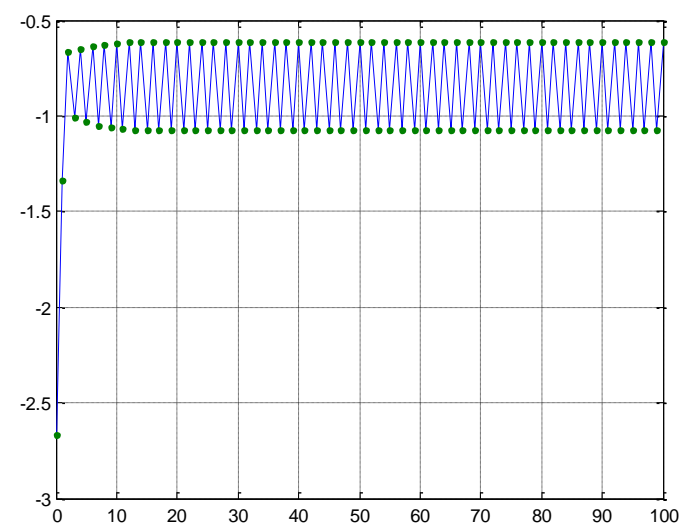

Figure 1: Orbit of $F(z)$ for $\left(z_{0}=-\mathbf{2 . 6 6 8 7 5 + 0 . 0 0 6 2 5 i ) ~ a t ~}\right.$ $\alpha=0.5, \beta=0.5, \mathbf{c}=0.1$

Table 2: Orbit of $\mathrm{F}(\mathrm{z})$ for $\left(\mathrm{z}_{0}=\mathbf{- 1 . 6 8 7 5 + 0 . 8 4 3 7 5}\right)$ at $\alpha=1$, $\beta=\mathbf{1}, \mathbf{c}=\mathbf{0 . 1}$

\begin{tabular}{|c|c|c|c|}
\hline $\begin{array}{c}\text { No. of } \\
\text { iterations }\end{array}$ & $|\mathrm{Tz}|$ & $\begin{array}{c}\text { No. of } \\
\text { iterations }\end{array}$ & $|\mathrm{Tz}|$ \\
\hline 1 & 17.4696 & 11 & 1.11051 \\
\hline 2 & 1.10000 & 12 & 1.11051 \\
\hline 3 & 1.11399 & 13 & 1.11051 \\
\hline 4 & 1.10956 & 14 & 1.11051 \\
\hline 5 & 1.11078 & 15 & 1.11051 \\
\hline 6 & 1.11043 & 16 & 1.11051 \\
\hline 7 & 1.11053 & 17 & 1.11051 \\
\hline 8 & 1.11050 & 18 & 1.11051 \\
\hline 9 & 1.11051 & 19 & 1.11051 \\
\hline 10 & 1.11051 & 20 & 1.11051 \\
\hline
\end{tabular}

Here we observe that the value converges to a fixed point $\mathbf{1 . 1 1 0 5 1}$ after 8 iterations.

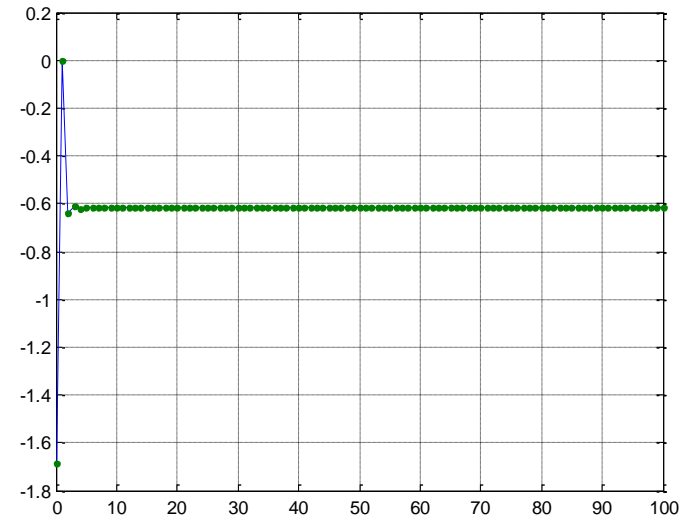

Figure 2: Orbit of $F(z)$ for $\left(z_{0}=\mathbf{- 1 . 6 8 7 5 + 0 . 8 4 3 7 5 )}\right.$ at $\alpha=1$, $\beta=1, c=0.1$ 
Table 3: Orbit of $F(z)$ for $\left(z_{0}=-2.24375+1.3375 i\right)$ at $\alpha=0.3, \beta=0.2, \mathbf{c}=0.1$

\begin{tabular}{|c|c|c|c|}
\hline $\begin{array}{c}\text { No. of } \\
\text { iterations }\end{array}$ & $|\mathrm{Tz}|$ & $\begin{array}{c}\text { No. of } \\
\text { iterations }\end{array}$ & $|\mathrm{Tz}|$ \\
\hline 1 & 58829601051.3444 & 16 & 1.3454 \\
\hline 2 & 227.4253 & 17 & 1.3503 \\
\hline 3 & 2.0861 & 18 & 1.3476 \\
\hline 4 & 10.1152 & 19 & 1.3491 \\
\hline 5 & 1.2891 & 20 & 1.3483 \\
\hline 6 & 1.0992 & 21 & 1.3487 \\
\hline 7 & 1.6548 & 22 & 1.3485 \\
\hline 8 & 1.1541 & 23 & 1.3486 \\
\hline 9 & 1.8486 & 24 & 1.3485 \\
\hline 10 & 1.2591 & 25 & 1.3486 \\
\hline 11 & 1.425 & 26 & 1.3485 \\
\hline 12 & 1.3165 & 27 & 1.3485 \\
\hline 13 & 1.3687 & 28 & 1.3485 \\
\hline 14 & 1.3383 & 29 & 1.3485 \\
\hline 15 & 1.3544 & 30 & 1.3485 \\
\hline
\end{tabular}

Here we observe that the value converges to a fixed point 1.3485 after 25 iterations.

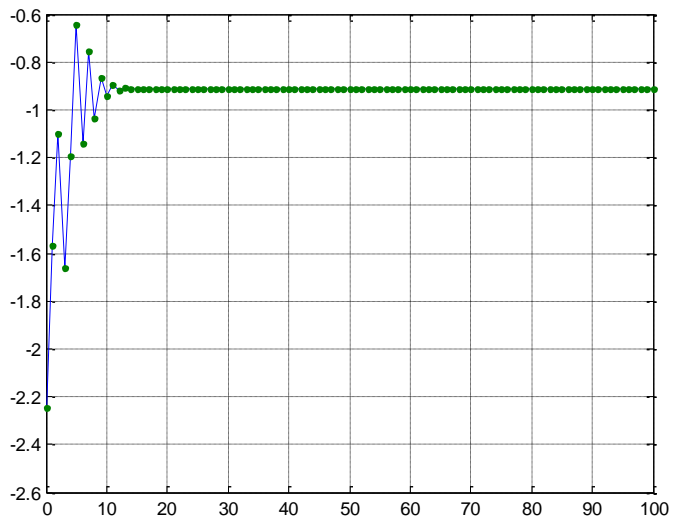

Figure 3: Orbit of $F(z)$ for $\left(z_{0}=-2.24375+1.3375 i\right)$ at

$$
\alpha=0.3, \beta=0.2, \mathbf{c}=0.1
$$

\section{GEOMETRY OF RELATIVE}

\section{SUPERIOR MANDELBROT SETS AND}

\section{RELATIVE SUPERIOR JULIA SETS}

\section{Relative Superior Mandelbrot Sets}

- In case of quadratic function, the central body is divided into three parts or we can say it looks like a flower having 3 leaves. It is seen that the body is symmetric along the real axis only. Each part has one secondary lobe which is approximately equal in size.

- In case of cubic function, the central body is divided into 5 equal parts or we can say it looks like a flower having 5 leaves .Each part have one secondary lobe of different sizes. It is seen that the body is symmetric along the real axis only. For $\alpha=0.3, \beta=0.5$, the size of the secondary lobes is larger as compared to other values.

- In case of biquadratic function, the central body is divided into seven equal parts or we can say it looks like a flower having 7 equal size leaves. Each part having one secondary lobe of different sizes. It is seen that the body is symmetric along the real axis only.

\section{Relative Superior Julia Sets}

- Relative Superior Julia Sets for the transcendental function $\cosh (\mathrm{z})$ appears to follow law of having $2 \mathrm{n}$ wings. These sets are symmetric along both the axes i.e. along real and imaginary axis.

- For quadratic function the Relative Superior Julia Set is divided into four wings having red central body. These sets are symmetric along both the axes.

- For cubic function the Relative Superior Julia Set is divided into six wings having reflectional and rotational symmetry, along with a larger red central region.

- For biquadratic function the Relative Superior Julia Set is divided into eight wings possessing the reflectional and rotational symmetry and it is having a larger escape region as compared to quadratic and cubic function.

- It is also observed from the graphical study of fixed points of Relative Superior Julia Sets that the convergence for

$\alpha=0.5, \beta=0.5$ and $\alpha=1, \beta=1 \quad$ is quite fast for all polynomials in comparison to the convergence for other values.

\section{GENERATION OF RELATIVE SUPERIOR MANDELBROT SETS}

We generated the Relative Superior Mandelbrot sets. We present here some beautiful filled Relative Superior Mandelbrot sets for quadratic, cubic and biquadratic function.

\subsection{Relative Superior Mandelbrot sets for Quadratic function}

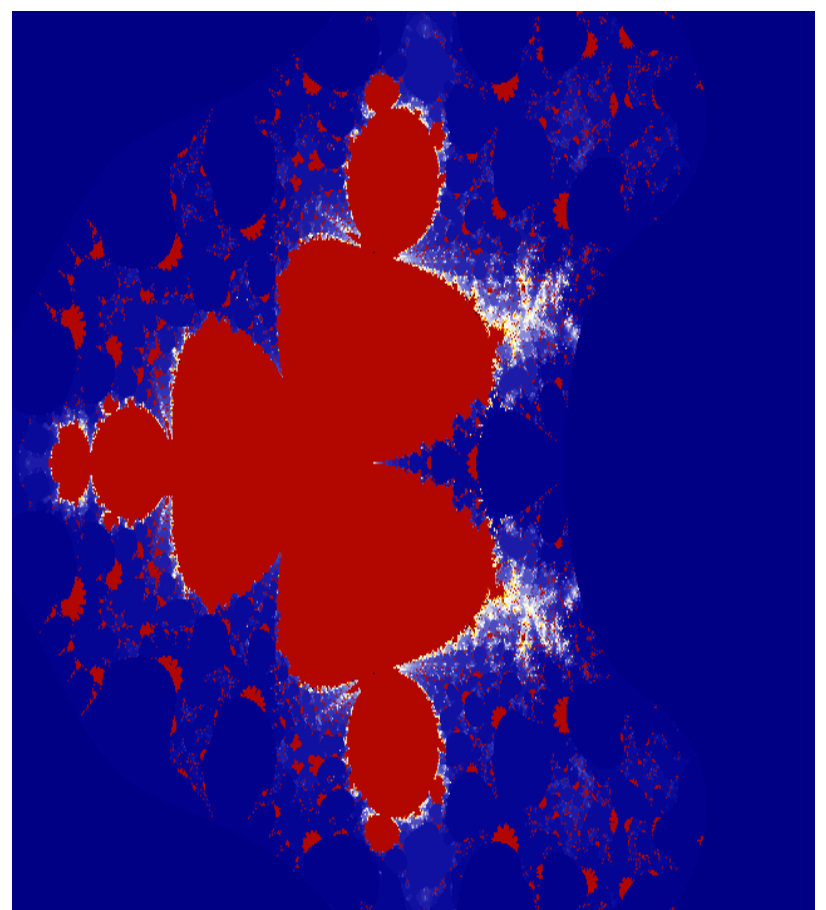

Figure 1: Relative Superior Mandelbrot Set for $\alpha=\beta$ $=0.5 \& \mathrm{c}=\mathbf{- 0 . 8 1 2 5}-\mathbf{0 . 1 1 2 5 i}$ 


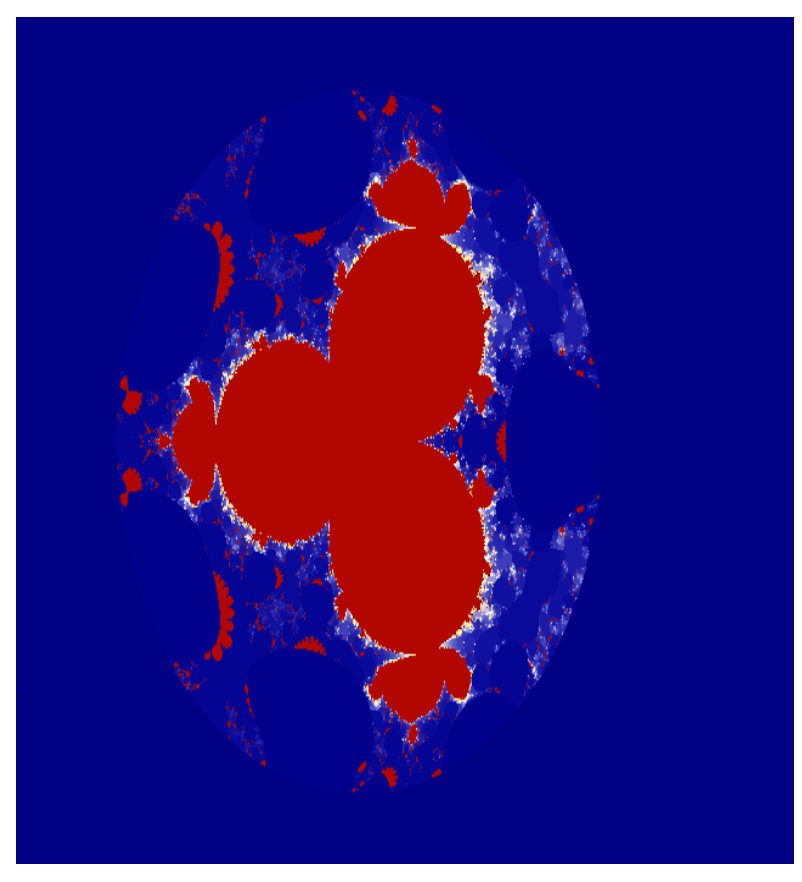

Figure 2: Relative Superior Mandelbrot Set for $\alpha=0.8$, $\beta=0.1, \mathbf{c}=-2.6875-0.0625 \mathrm{i}$

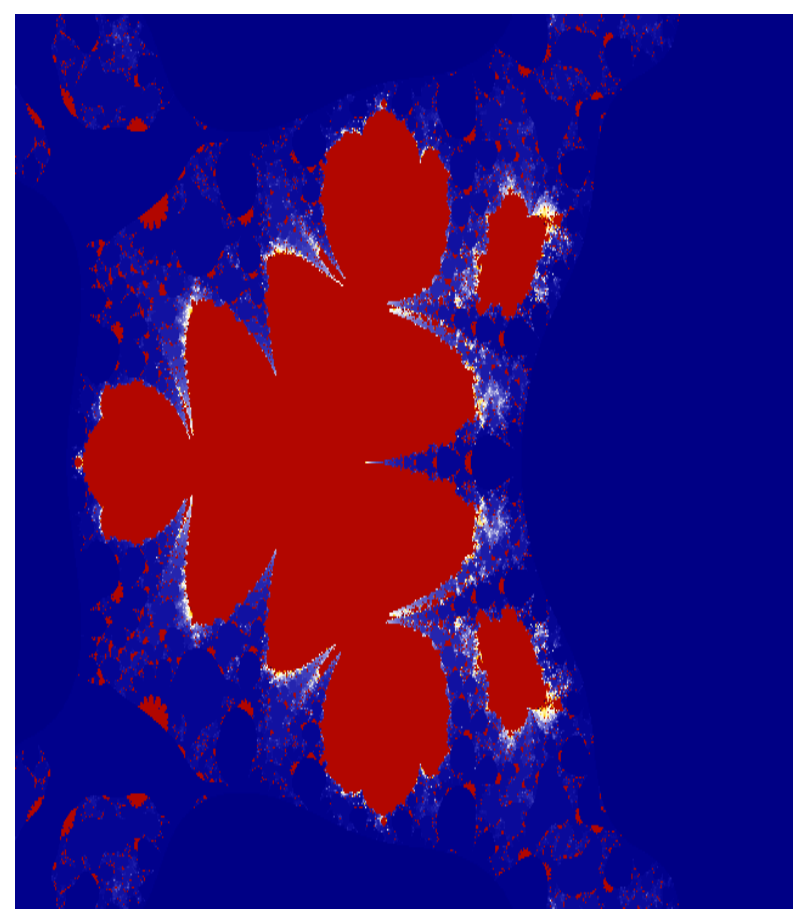

Figure 3: Relative Superior Mandelbrot Set for $\alpha=\mathbf{0 . 3}$, $\beta=0.7, \mathbf{c}=-\mathbf{0 . 3 5 6 2 5}-1.65 \mathrm{i}$

\subsection{Relative Superior Mandelbrot Sets for} Cubic function

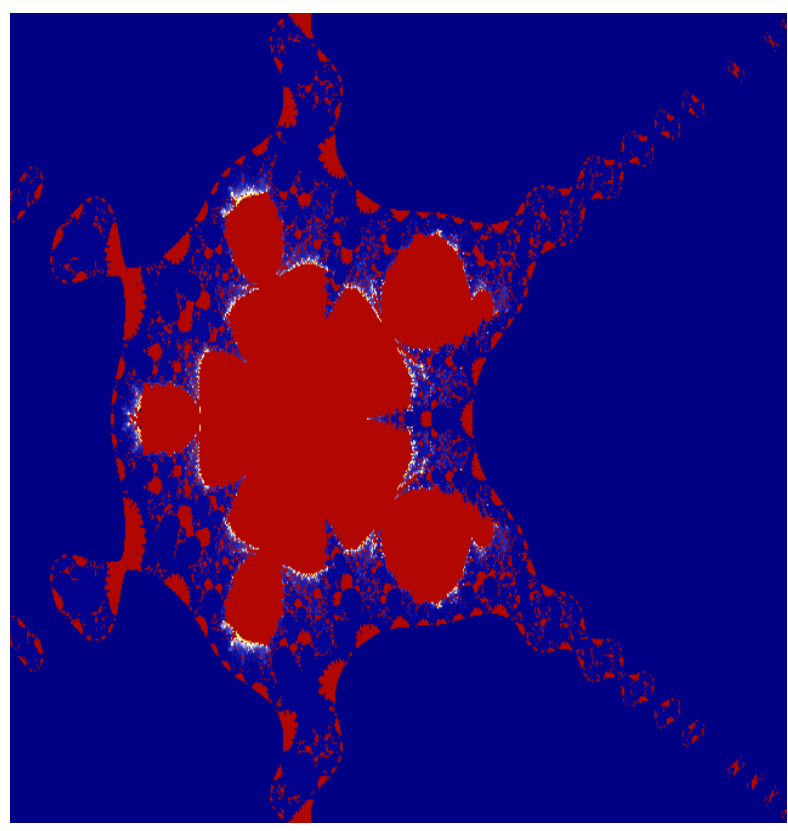

Figure 1: Relative Superior Mandelbrot Set for $\alpha=0.5$, $\beta=0.7, \mathbf{c}=-0.9+1.04375 i$

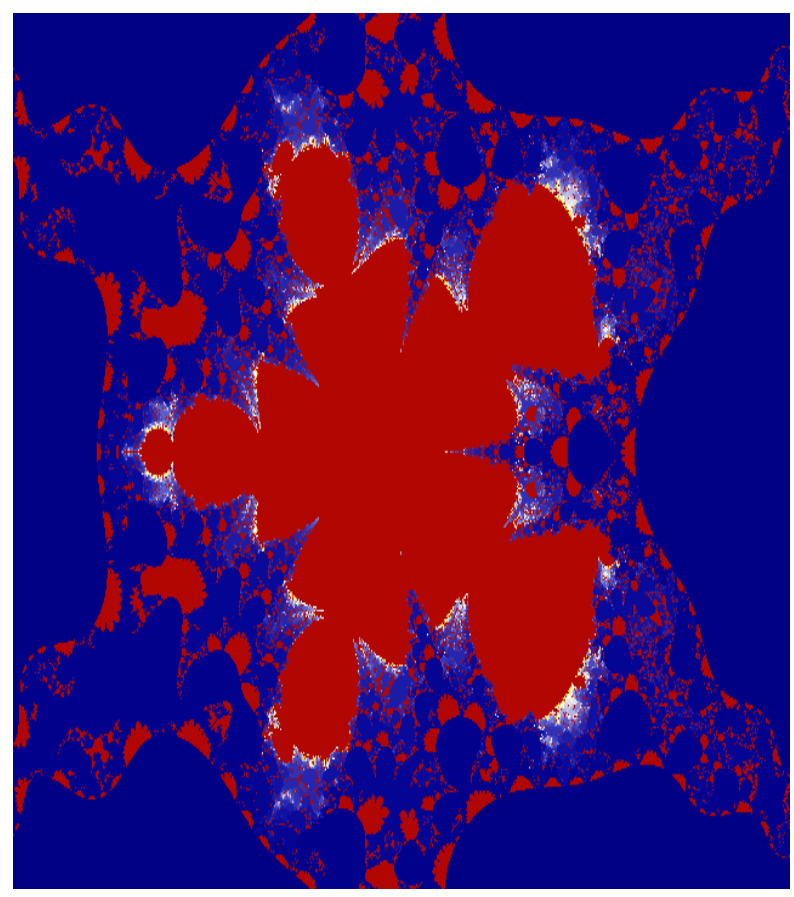

Figure 2: Relative Superior Mandelbrot Set for $\alpha=\mathbf{0 . 3}$, $\beta=0.5, c=-1.31875+1.225 i$ 


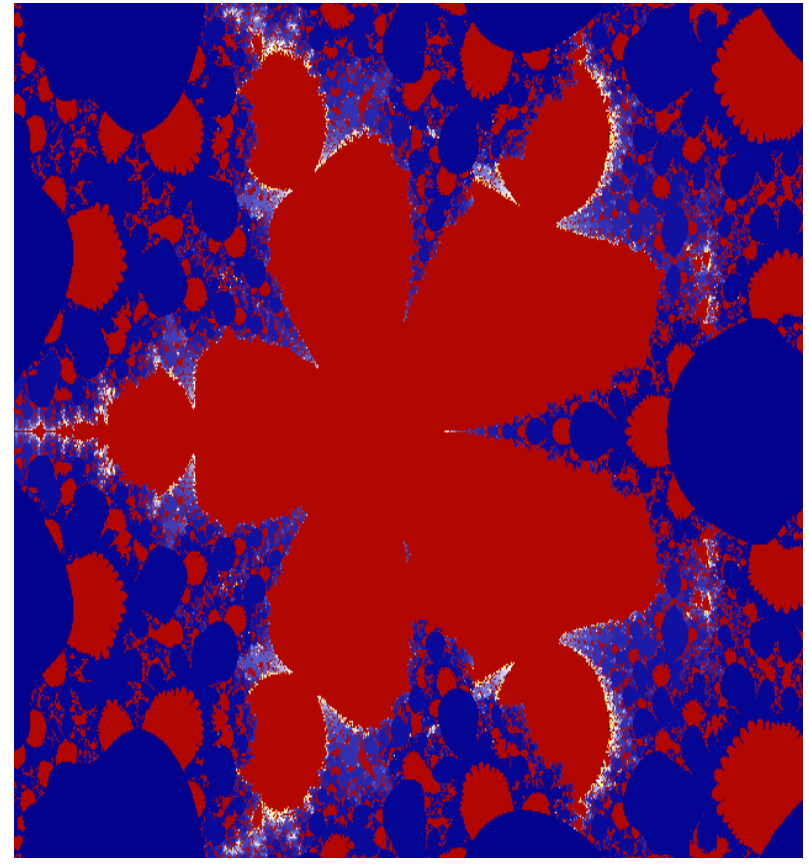

Figure 3: Relative Superior Mandelbrot Set for $\alpha=0.3$, $\beta=0.2, \mathbf{c}=-\mathbf{1 . 9 2 5 - 1 . 7 3 7 5 i}$

\subsection{Relative Superior Mandelbrot sets for} biquadratic function

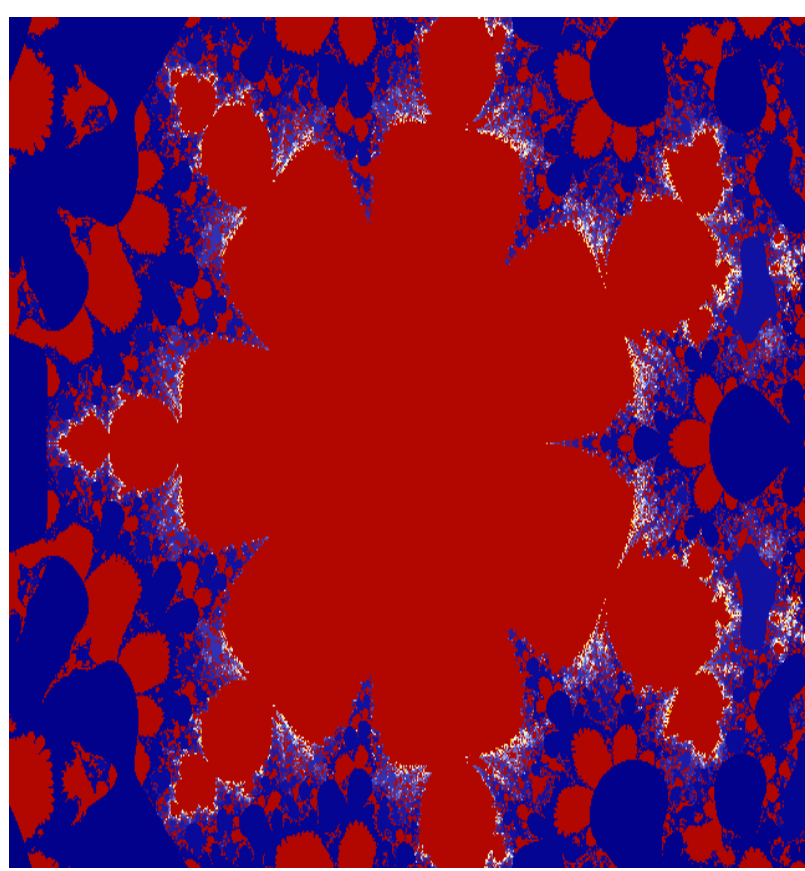

Figure 1: Relative Superior Mandelbrot Set for $\alpha=0.5$, $\beta=0.5, c=-2.66875+0.00625 i$

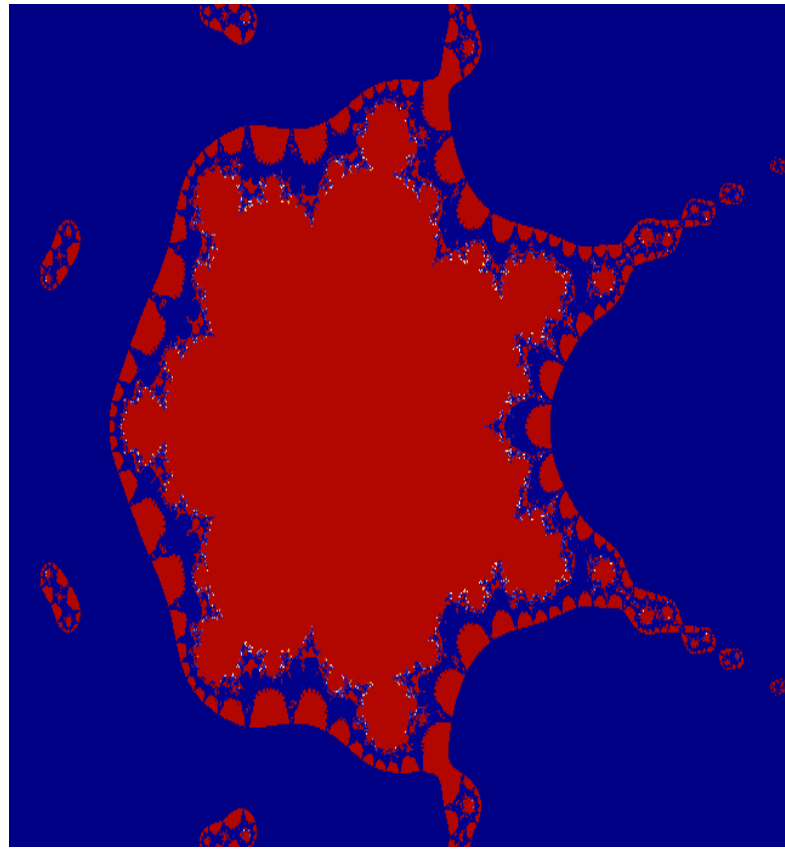

Figure 2: Relative Superior Mandelbrot Set for $\alpha=1, \beta$ $=1, c=-1.6875+0.84375 i$

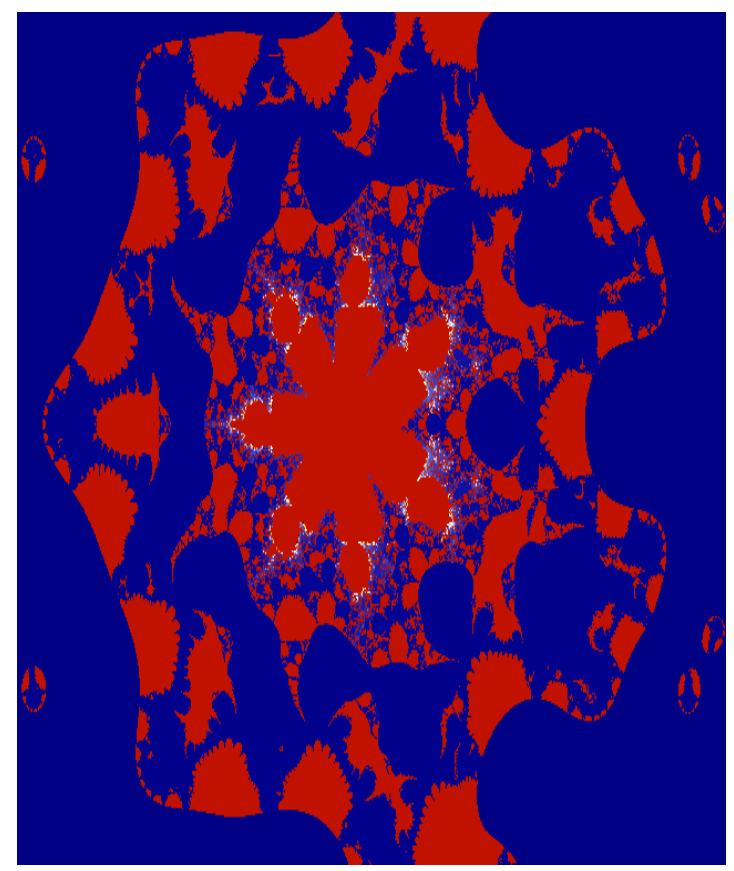

Figure 3: Relative Superior Mandelbrot Set for $\alpha=0.3$, $\beta=0.2, c=-2.24375+1.3375 i$

\section{GENERATION OF RELATIVE SUPERIOR JULIA SETS}

We generated the Relative Superior Julia sets. We have presented here some beautiful filled Relative Superior Julia sets for quadratic, cubic and biquadratic function. 
7.1 Relative Superior Julia sets for Quadratic function

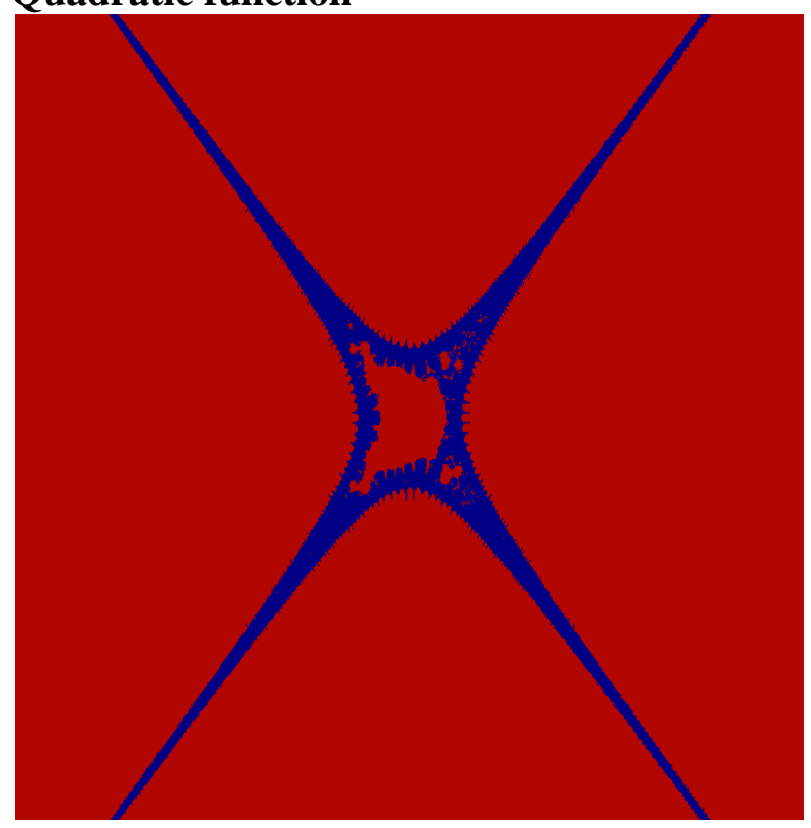

Figure 1: Relative Superior Julia Set for $\alpha=\beta=0.5 \&$ c

$$
=\mathbf{- 0 . 8 1 2 5 - 0 . 1 1 2 5 i}
$$

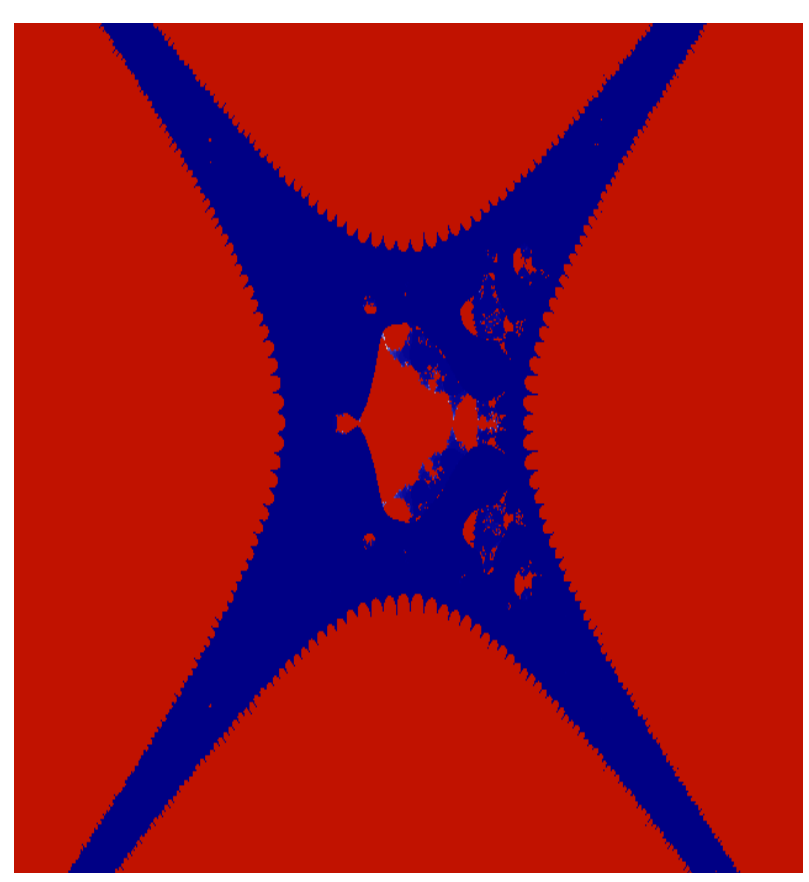

Figure 2: Relative Superior Julia Set for $\alpha=0.8$, $\beta=0.1, \mathbf{c}=-2.6875-0.0625 \mathrm{i}$

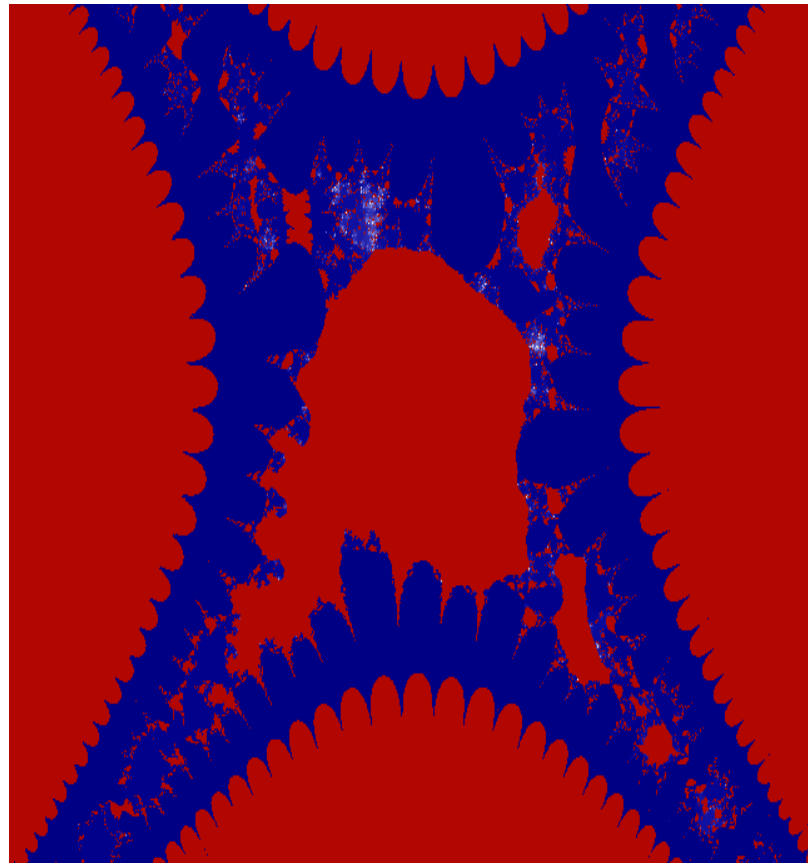

Figure 3: Relative Superior Julia Set for $\alpha=0.3, \beta=0.7$, $c=-0.35625-1.65 i$

\subsection{Relative Superior Julia Sets for Cubic} function

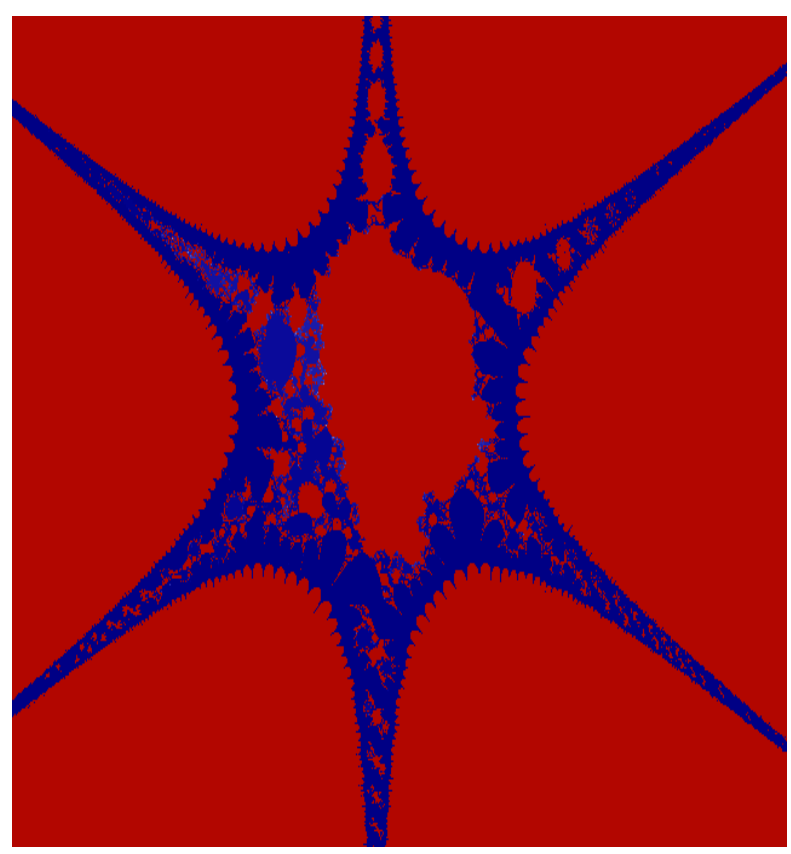

Figure 1: Relative Superior Julia Set for $\alpha=0.5, \beta=0.7$, $c=-0.9+1.04375 i$ 


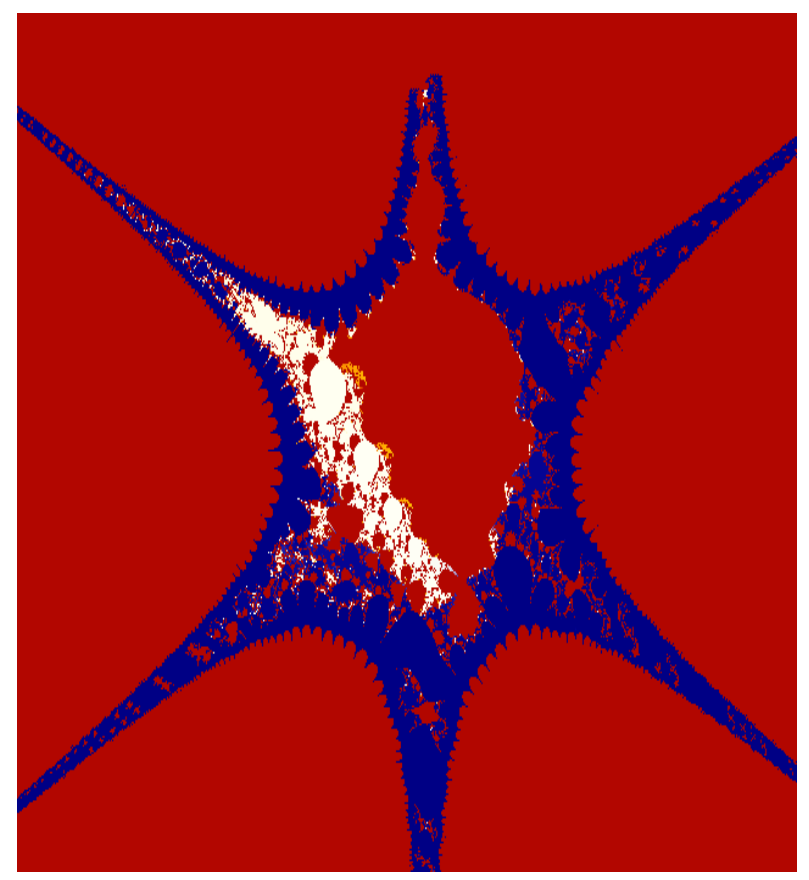

Figure 2: Relative Superior Julia Set for $\alpha=0.3, \beta=0.5$,

$$
c=-1.31875+1.225 i
$$

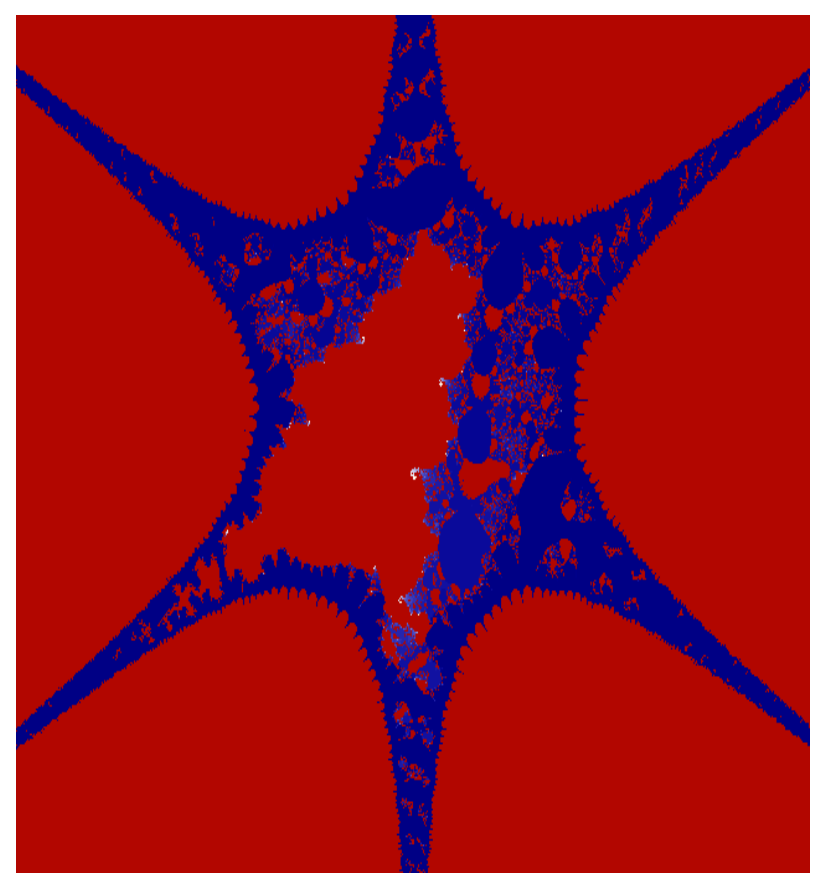

Figure 3: Relative Superior Julia Set for $\alpha=0.3, \beta=0.2$, $c=\mathbf{- 1 . 9 2 5 - 1 . 7 3 7 5 i}$

7.3 Relative Superior Julia sets for biquadratic function

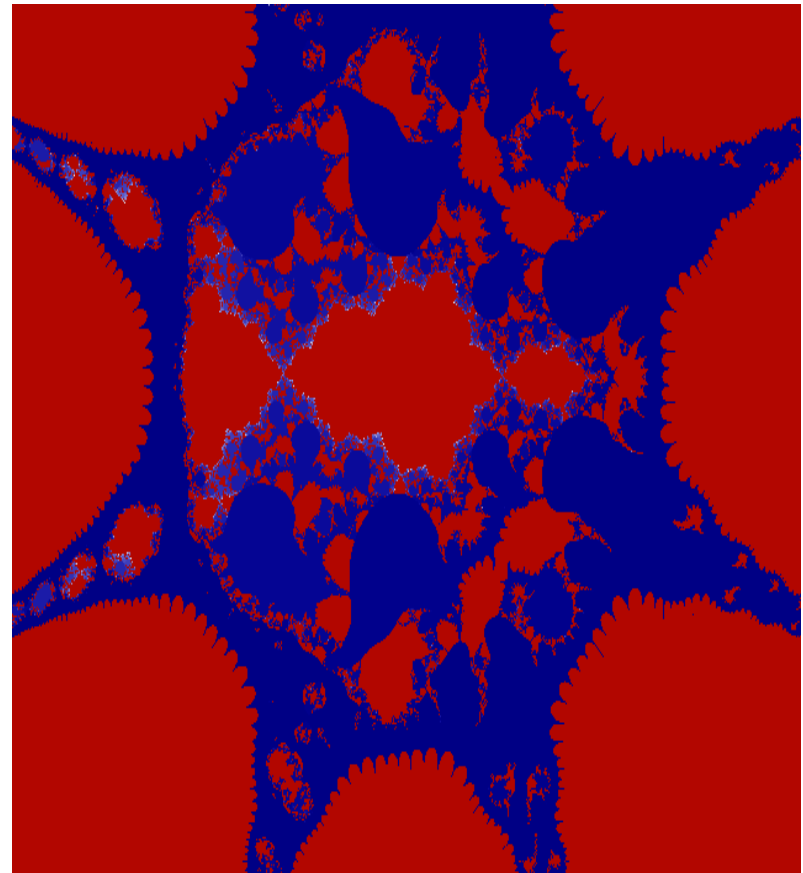

Figure 1: Relative Superior Julia Set for $\alpha=0.5, \beta=0.5$, c $=-2.66875+0.00625 \mathrm{i}$

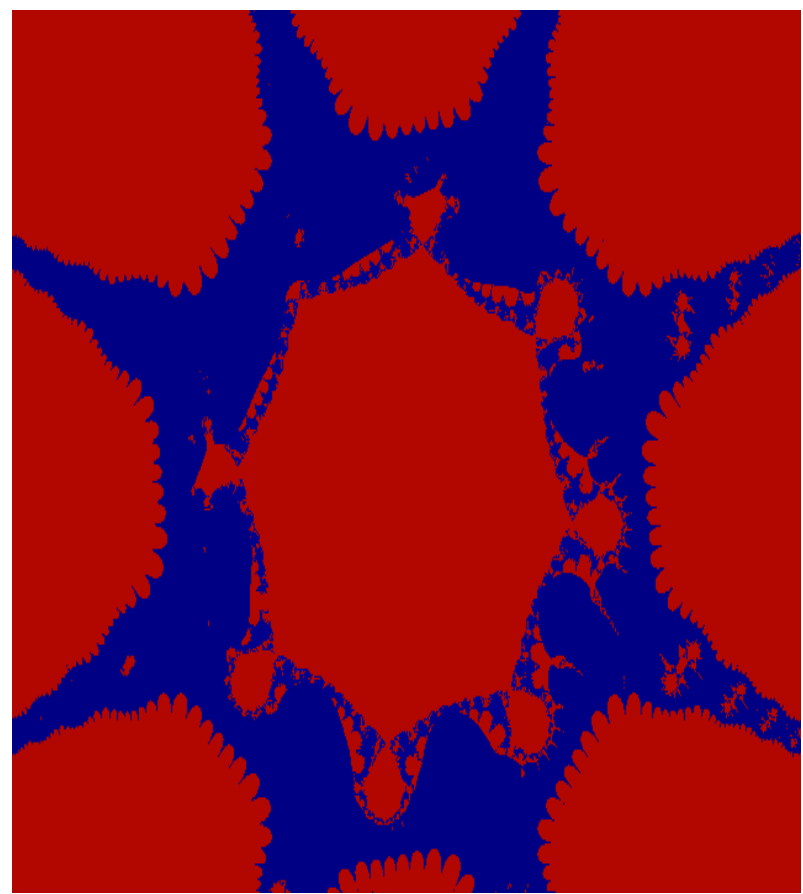

Figure 2: Relative Superior Julia Set for $\alpha=1, \beta=1, \mathrm{c}=$ $1.6875+0.84375 \mathrm{i}$ 


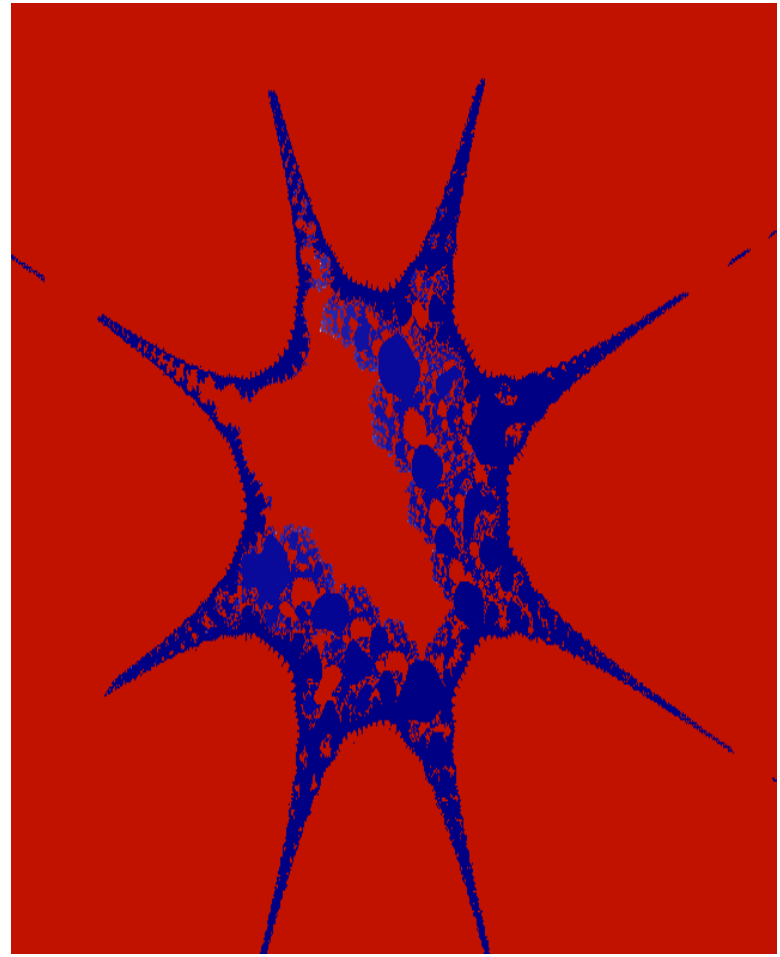

Figure 3: Relative Superior Julia Set for $\alpha=0.3, \beta=0.2$,

$c=-2.24375+1.3375 i$

\section{CONCLUSION}

In this paper we studied the hyperbolic cosine function which is one of the members of transcendental family. The fixed point 0 for $S(z)=\cosh \left(z^{n}\right)+z+c=0$ also satisfies $S^{\prime}(0)=1$. Relative Superior Mandelbrot sets for the hyperbolic transcendental function $\cosh (\mathrm{z})$ appear like beautiful flowers having the symmetry of $2 \mathrm{n}-1$ petals/leaves while Relative Superior Julia Sets appears to follow law of having $2 \mathrm{n}$ wings. The surrounding region of the Mandelbrot set appears to be an invariant Cantor set in the form of curve or "hair" that extends to $\infty$. The orbit of any point on hair tends to infinity under iteration. Here the geometry of hairs is quite similar to that of exponential family and hence showed the property of transcendental function. The region filled up with large number of escaping points represents Julia set plane.

\section{REFERENCES}

[1] Suman Joshi, Dr.Yashwant Singh Chauhan and Dr. Ashish Negi, "New Julia and Mandelbrot Sets for Jungck Ishikawa Iterates" International Journal of Computer Trends and Technology (IJCTT), vol.9, no.5, pp.209216, 2014.

[2] Suman Joshi, Dr.Yashwant Singh Chauhan and Dr.Priti Dimri ,"Complex Dynamics of Multibrot Sets for Jungck Ishikawa Iteration" International Journal of Research in Computer Applications and Robotics (IJRCAR), vol. 2, no. 4, pp. 12-22, 2014.

[3] Suman Pant, Dr.Yashwant Singh Chauhan and Dr.Priti Dimri "Complex Dynamics of Sine Function using Jungck Ishikawa Iteration" International Journal of Computer Applications (IJCA), vol. 94, no. 10, pp. 4454, 2014.
[4] E. F. Glynn, "The Evolution of the Gingerbread Mann",Computers and Graphics 15,4 (1991), 579 -582.

[5] U. G. Gujar and V. C. Bhavsar, "Fractals from $z=z^{\alpha}+c$

in the Complex c-Plane", Computers and Graphics 15, (1991), 441-449.

[6] U. G. Gujar, V. C. Bhavsar and N. Vangala, "Fractalsfrom $\mathrm{z}=\mathrm{z}^{\alpha}+\mathrm{c}$ in the Complex z-Plane", Computersand Graphics 16, 1 (1992), 45-49.

[7] R. Chugh and V. Kumar, "Strong Convergence and Stability results for Jungck-SP iterative scheme, International Journal of Computer Applications, vol. 36,no. 12, 2011.

[8] S. Ishikawa, "Fixed points by a new iteration method", Proc. Amer. Math. Soc.44 (1974), 147-150.

[9] G. Julia, "Sur 1' iteration des functions rationnelles", JMath Pure Appli. 8 (1918), 737-747

[10] B. B. Mandelbrot, The Fractal Geometry of Nature, W. H.Freeman, New York, 1983.

[11] Eike Lau and Dierk Schleicher, "Symmetries of fractals revisited." Math. Intelligencer (18) (1) (1996), $45-$ 51.MR1381579 Zbl 0847.30018.

[12] J. Milnor, "Dynamics in one complex variable; Introductory lectures", Vieweg (1999).

[13]Shizuo Nakane, and Dierk Schleicher, "Non-local connectivity of the tricorn and multicorns", Dynamical systems and chaos (1) (Hachioji, 1994), 200-203, World Sci. Publ., River Edge, NJ, 1995. MR1479931.

[14] Rajeshri Rana, Yashwant S Chauhan and Ashish Negi.Article: Non Linear Dynamics of Ishikawa Iteration. International Journal of Computer Applications 7(13):43-49, October 2010. Published By Foundation of Computer Science.ISBN: 978-93-80746-97-5.

[15] Ashish Negi, "Generation of Fractals and Applications", Thesis, Gurukul Kangri Vishwvidyalaya, (2005).

[16] M.O.Olatinwo, "Some stability and strong convergence results for the Jungck-Ishikawa iteration process,"Creative Mathematics and Informatics, vol. 17, pp. 33-42, 2008.

[17] Peitgen, H.O., Jurgens, H. and Saupe, D., Chaos and Fractals: New Frontiers of Science. Springer-Verlag, New York, Inc, 2004.

[18] A. G. D. Philip: "Wrapped midgets in the Mandelbrot set", Computer and Graphics 18 (1994), no. 2, 239-248.

[19] Shizuo Nakane, and Dierk Schleicher, "On multicorns and unicorns: I. Antiholomorphic dynamics. Hyperbolic components and real cubic polynomials", Internat. J. Bifur. Chaos Appl. Sci. Engrg, (13) (10) (2003), $2825-$ 2844.

[20] M.O.Osilike, "Stability results for Ishikawa fixed point iteration procedure", Indian Journal of Pure and Appl. Math., 26(1995), 937-945. 